\title{
Underweight and Obesity in Low Birth Weight Children in Early Infancy in Japan
}

\author{
Rena Kato $^{1}$, Masaru Kubota ${ }^{1}$, Hiromi Saito ${ }^{1}$, Yukihiro Takahashi ${ }^{2}$ \\ ${ }^{1}$ Department of Human Life and Environment, Nara Women's University, Nara, Japan \\ ${ }^{2}$ Department of Neonatal Intensive Care Unit, Nara Medical University Hospital, Nara, Japan \\ Email: masaru kubota@chime.ocn.ne.jp
}

Received 19 February 2015; accepted 8 March 2015; published 11 March 2015

Copyright (C) 2015 by authors and Scientific Research Publishing Inc.

This work is licensed under the Creative Commons Attribution International License (CC BY). http://creativecommons.org/licenses/by/4.0/

(c) (7) Open Access

\section{Abstract}

Introduction: Although there are several reports on the prevalence of underweight or obesity in low birth weight (LBW, $<2.5 \mathrm{~kg}$ ) children, there are few longitudinal studies from birth to early infancy. Methods: We enrolled 177 (93 boys) LBW and 2485 (1267 boys) normal birth weight (NBW, $\geq 2.5$ and $<4.0 \mathrm{~kg}$ ) children. Height and weight data at birth and at 1.5, 3.5, and 5 years were obtained from mother-health child records. Underweight and obesity were defined as $<5^{\text {th }}$ percentile and $\geq 90^{\text {th }}$ percentile of the body mass index (BMI), respectively, based on reference values for Japanese children. Results: LBW children had accelerated growth from birth to age 3.5 years, but at Age 5, both sexes had significantly lesser height and weight z-scores, with notably lesser BMI percentile scores for girls, compared with NBW children. The prevalence of underweight was significantly higher in the LBW children throughout the study period. There were no significant differences in the prevalence of obesity between the two groups, except for at birth. Multiple regression analysis revealed that small-for-gestational age was associated with underweight at Age 5 years. Conclusions: This study indicates that, up to Age 5, underweight is a more serious problem than obesity in LBW children. Our results suggest that careful observation of growth from early infancy is necessary to prevent the occurrence of underweight in early infancy.

\section{Keywords}

Growth, Low Birth Weight, Obesity, Small-for-Gestational Age, Underweight

\section{Introduction}

Advances in perinatal care over the past two decades have reduced the mortality rate associated with very low birth weight (VLBW, <1.5 kg) [1] [2]. However, VLBW children are at high risk of adverse long-term medical 
and developmental outcomes [3]. In Japan, unlike other developed counties, the rate of low birth weight (LBW, $<2.5 \mathrm{~kg}$ ) has almost doubled from $5 \%$ in the late 1970 s to approximately $10 \%$ in the late 2000s [4]. In 2012, the rate of LBW was 9.6\% in Japan [5], which was the highest rate among developed countries [4].

After initial postnatal growth failure, most preterm infants exhibit catch-up growth in weight, height, and head circumference, generally starting early in the neonatal period and with catch-up occurring by early infancy [6] [7]. However, some investigators have reported delayed catch-up growth to childhood [7] [8] or adolescence [9]. In addition, Roberts et al. [10] reported that height at age 2 was a good predictor of height at age 18 in extremely preterm children whose gestational age was less than 28 weeks, when mid parental heights were used as a reference. Taken together, these data suggest that monitoring growth in infancy is important for predicting subsequent catch-up growth in LBW children.

A large body of reports exists on the association of LBW and postnatal growth in early infancy with later health consequences in adolescence or in adulthood [11]-[18]. This is particularly so since the Barker hypothesis [19] and the developmental origins of health and disease model [20] were proposed. Barker et al. [13] documented the association of LBW and low weight gain in the first year of life with death from ischemic heart disease. Recent studies focusing on excessive weight gain in early life have also shown that LBW combined with rapid weight gain in early infancy is associated with greater risk for the development of obesity [14], hypertension [15], insulin resistance [16] [17], and cardiovascular disease [18]. Therefore, growth among LBW infants is thought to influence the occurrence of noncommunicable diseases in later life.

Based on this knowledge, the present study aimed to follow-up the growth of LBW and normal birth weight (NBW, $\geq 2.5$ and $<4.0 \mathrm{~kg}$ ) children from birth to 5 years of age, longitudinally. In addition to comparing the two groups, we aimed to determine the prevalence of both underweight and obesity in relation to the physical characteristics of LBW children at birth.

\section{Methods}

\subsection{Low Birth Weight Children}

We retrospectively included 1635 patients admitted to the neonatal intensive care unit of the Nara Medical University Hospital, Nara, Japan, from 1994 to 2007. Current addresses were missing for 312 patients, and the birth weight of 675 patients were $\geq 2.5 \mathrm{~kg}$. Consequently, we sent questionnaires to the parents of 648 children whose birth weight was $<2.5 \mathrm{~kg}$ between September 2012 and December 2013, and 240 questionnaires (37.0\%) were returned. We excluded the questionnaires for patients with cerebral palsy, trisomy 8 syndrome, and DiamondBlackfan anemia and patients who received growth hormone. Therefore, a total of 177 children (93 boys, 84 girls) were enrolled. Perinatal and birth data were collected from medical charts, and values of height and weight from birth to 5 years of age were obtained from mother-health child records maintained by the mother.

This project was approved by the ethical and epidemiological committees of both the Nara Women's University and Nara Medical University Hospital. In the questionnaire, we explained that parental consent was implied by completing and returning it.

\subsection{Normal Birth Weight Controls}

We enrolled 2485 children (1267 boys, 1218 girls) aged 5 years old who were attending kindergarten or nursery school in the Nara Prefecture of Japan. Their birth weight was required to be $\geq 2.5 \mathrm{~kg}$ and $<4.0 \mathrm{~kg}$. The details of these participants and the method of data collection are available elsewhere [21].

\subsection{Definition of Underweight and Obesity}

Body mass index (BMI) was calculated as body weight in kilograms divided by height in meters squared $\left(\mathrm{kg} / \mathrm{m}^{2}\right)$. We defined underweight and obesity by the BMI as that less than the $5^{\text {th }}$ percentile and that equal to or more than the $90^{\text {th }}$ percentile, respectively, based on the standards of the Japanese Association for Human Auxology [22]. A BMI below the $5^{\text {th }}$ percentile has been widely used to define childhood and adolescent underweight [23]-[25]. Cole et al. [26] reported that a BMI of 25.0 at age 18 corresponded to the $90^{\text {th }}$ percentile for males and the $88^{\text {th }}$ percentile for females. Therefore, considering that a BMI of $\geq 25.0$ defines obesity in Japanese adults [27], we adopted the $90^{\text {th }}$ BMI percentile at each age as a suitable cut-off value for obesity. 


\subsection{Data Analysis}

Differences by sex in the perinatal and birth data were examined by the Student $t$-test or Fisher exact test. The Student $t$-test was used to compare the physical characteristics from birth to Age 5 years between the LBW and NBW children. The prevalence of underweight and obesity in LBW and NBW children was compared by the Fisher exact test. Comparison of the physical characteristics of LBW children at birth for those who were underweight, normal weight, and obese at Age 5 was also made using the Student $t$-test or Fisher exact test. The association between underweight at Age 5 and physical characteristics at birth were determined by multiple logistic regression analysis, with odds ratios (ORs) and confidence intervals (CIs). The characteristics of LBW children included sex, birth weight, height, gestational age, the presence of small-for-gestational age (SGA), and multiple births in LBW children. Data analysis was performed using Excel Statistics, version 2010 (SSRI Co., Ltd., Tokyo, Japan). $P$ values less than 0.05 were considered significant.

\section{Results}

\subsection{Physical Characteristics at Birth in Low Birth Weight Children}

Physical characteristics at birth, including birth weight and height, gestational age, and the prevalence of SGA and multiple births, are shown in Table 1. Among these data, a significant difference was only found between the sexes for the prevalence of SGA.

\subsection{Comparison of Physical Characteristics at Birth and at 1.5, 3.5, and 5 Years of Age between Low Birth Weight and Normal Birth Weight Children}

Table 2 indicates the longitudinal changes in height and weight z-scores, increments of height and weight zscores, and BMI percentiles from birth to Age 5 in LBW and NBW children. LBW children exhibited significantly higher growth from birth to age 3.5 compared with NBW children, but still had significantly lower height and weight z-scores than NBW children of either sex at Age 5. In contrast, BMI percentiles at Age 5 are statistically smaller in only LBW girls.

\subsection{Comparison of the Prevalence of Underweight and Obesity between Low Birth Weight and Normal Birth Weight Children}

The prevalence of underweight was significantly higher in LBW children than in NBW children in both sexes, except for boys at age 1.5 (Table 3). In addition, no statistical differences existed in the prevalence of obesity between LBW and NBW children, except for at birth. Although not statistically significant, the prevalence of obesity tended to be higher in LBW boys and lower in LBW girls aged 1.5, 3.5, and 5 years.

Table 1. Physical characteristics at birth in low birth weight children.

\begin{tabular}{ccccc}
\hline & Total $(\mathrm{n}=177)$ & Boys $(\mathrm{n}=93)$ & Girls $(\mathrm{n}=84)$ & $P$-value \\
\hline Birth weight $(\mathrm{kg} \pm \mathrm{SD})$ & $1.64 \pm 0.47$ & $1.65 \pm 0.45$ & $1.63 \pm 0.50$ & $0.72^{\mathrm{b}}$ \\
$\geq 1.5 \mathrm{~kg},<2.5 \mathrm{~kg}(\%)$ & $112(63.3)$ & $60(64.5)$ & $52(61.9)$ & \\
$\geq 1.0 \mathrm{~kg},<1.5 \mathrm{~kg}(\%)$ & $46(26.0)$ & $24(25.8)$ & $22(26.2)$ & $0.90^{\mathrm{c}}$ \\
$<1.0 \mathrm{~kg}(\%)$ & $19(10.7)$ & $9(9.7)$ & $10(11.9)$ & \\
Birth height (cm \pm SD) & $40.3 \pm 4.0$ & $40.3 \pm 3.8$ & $40.3 \pm 4.3$ & $0.93^{\mathrm{b}}$ \\
Gestational age (wk $\pm \mathrm{SD})$ & $32.7 \pm 3.6$ & $32.3 \pm 3.3$ & $33.2 \pm 3.8$ & $0.09^{\mathrm{b}}$ \\
SGA $(\%)$ & $42(23.7)$ & $16(17.2)$ & $26(31.0)$ & $<0.05^{\mathrm{c}}$ \\
Muptiplebirths (\%) & $34(19.2)$ & $18(19.4)$ & $16(19.0)$ & $0.56^{\mathrm{c}}$ \\
\hline
\end{tabular}

${ }^{\text {a } S G A: ~ S m a l l ~ f o r ~ g e s t a t i o n a l ~ a g e, ~ d e f i n e d ~ a s ~ a ~ s e x-s p e c i f i c ~ b i r t h ~ h e i g h t ~ a n d ~ w e i g h t ~ b e l o w ~ t h e ~} 10^{\text {th }}$ percentile gestational age of the Japanese standard; 'The difference between genders was examined by the Student's $t$-test; ${ }^{\mathrm{C}}$ The difference between genders was examined by the Fisher's exact test. 
Table 2. Comparison of the physical characteristics at each time point between low and normal birth weight children.

\begin{tabular}{|c|c|c|c|c|c|c|}
\hline & \multicolumn{2}{|c|}{ Boys } & \multirow{2}{*}{$P$-value ${ }^{\text {a }}$} & \multicolumn{2}{|c|}{ Girls } & \multirow{2}{*}{$P$-value ${ }^{\mathrm{a}}$} \\
\hline & LBW (n = 93) & NBW $(n=1267)$ & & LBW $(n=84)$ & NBW $(n=1218)$ & \\
\hline \multicolumn{7}{|c|}{ Height Z-score } \\
\hline Birth & $-4.12 \pm 1.8$ & $0.17 \pm 0.94$ & $<0.001$ & $-3.91 \pm 2.07$ & $0.14 \pm 0.98$ & $<0.001$ \\
\hline $1.5 \mathrm{y}$ & $-0.84 \pm 2.1$ & $0.17 \pm 1.61$ & $<0.001$ & $-0.81 \pm 1.70$ & $0.17 \pm 1.66$ & $<0.001$ \\
\hline $3.5 \mathrm{y}$ & $-0.67 \pm 1.3$ & $-0.05 \pm 1.29$ & $<0.001$ & $-0.50 \pm 1.26$ & $0.04 \pm 1.21$ & $<0.001$ \\
\hline $5 y$ & $-0.35 \pm 1.3$ & $0.23 \pm 1.13$ & $<0.001$ & $-0.34 \pm 1.43$ & $0.25 \pm 1.18$ & $<0.001$ \\
\hline \multicolumn{7}{|c|}{ Increment of height Z-score } \\
\hline Birth - $1.5 \mathrm{y}$ & $3.28 \pm 2.71$ & $0.00 \pm 1.70$ & $<0.001$ & $3.10 \pm 2.24$ & $0.03 \pm 1.79$ & $<0.001$ \\
\hline $1.5 y-3.5 y$ & $0.17 \pm 2.12$ & $-0.22 \pm 1.18$ & $<0.05$ & $0.31 \pm 1.37$ & $-0.14 \pm 1.28$ & $<0.01$ \\
\hline $3.5 y-5 y$ & $0.32 \pm 0.92$ & $0.28 \pm 1.11$ & 0.34 & $0.16 \pm 0.80$ & $0.21 \pm 1.02$ & 0.26 \\
\hline \multicolumn{7}{|c|}{ Weight Z-score } \\
\hline Birth & $-3.37 \pm 1.12$ & $0.31 \pm 0.80$ & $<0.001$ & $-3.44 \pm 1.28$ & $0.11 \pm 0.76$ & $<0.001$ \\
\hline $1.5 \mathrm{y}$ & $-0.42 \pm 0.97$ & $0.18 \pm 1.06$ & $<0.001$ & $-0.67 \pm 1.37$ & $0.32 \pm 1.23$ & $<0.001$ \\
\hline $3.5 \mathrm{y}$ & $-0.51 \pm 0.99$ & $-0.03 \pm 0.95$ & $<0.001$ & $-0.53 \pm 1.16$ & $0.16 \pm 0.99$ & $<0.001$ \\
\hline $5 y$ & $-0.31 \pm 1.00$ & $0.11 \pm 1.00$ & $<0.001$ & $-0.54 \pm 0.99$ & $0.14 \pm 0.94$ & $<0.001$ \\
\hline \multicolumn{7}{|c|}{ Increment of weight Z-score } \\
\hline Birth - 1.5 y & $2.95 \pm 1.33$ & $-0.12 \pm 1.15$ & $<0.001$ & $2.77 \pm 1.50$ & $0.20 \pm 1.27$ & $<0.001$ \\
\hline $1.5 \mathrm{y}-3.5 \mathrm{y}$ & $-0.09 \pm 0.67$ & $-0.21 \pm 0.68$ & 0.06 & $0.14 \pm 0.80$ & $-0.16 \pm 0.83$ & $<0.001$ \\
\hline $3.5 y-5 y$ & $0.19 \pm 0.55$ & $0.14 \pm 0.65$ & 0.17 & $-0.01 \pm 0.60$ & $-0.02 \pm 0.60$ & 0.45 \\
\hline \multicolumn{7}{|c|}{ BMI \% tile } \\
\hline Birth & $6.9 \pm 13.6$ & $53.6 \pm 26.8$ & $<0.001$ & $6.6 \pm 14.5$ & $55.4 \pm 26.7$ & $<0.001$ \\
\hline $1.5 \mathrm{y}$ & $50.9 \pm 30.4$ & $51.8 \pm 27.6$ & 0.38 & $43.6 \pm 31.5$ & $55.5 \pm 28.1$ & $<0.001$ \\
\hline $3.5 \mathrm{y}$ & $49.5 \pm 31.9$ & $54.3 \pm 26.4$ & 0.08 & $38.5 \pm 29.2$ & $54.7 \pm 26.6$ & $<0.001$ \\
\hline $5 y$ & $45.8 \pm 30.5$ & $49.6 \pm 26.7$ & 0.12 & $34.2 \pm 27.4$ & $50.5 \pm 25.7$ & $<0.001$ \\
\hline
\end{tabular}

Data represents means \pm SD. LBW: Low Birth Weight; NBW: Normal Birth Weight. ${ }^{\mathrm{a} D i f f e r e n c e s ~ i n ~ t h e ~ p h y s i c a l ~ c h a r a c t e-~}$ ristics between LBW and NBW children were examined by the Student's $t$-test.

\subsection{Comparison of the Physical Characteristics at Birth Classified by a Body Status at Age 5 in Low Birth Weight Children}

We classified all LBW children into one of the three groups (underweight, normal weight, and obese) based on their BMI percentile at 5 years of age and compared the physical characteristics at birth between them. As shown in Table 4, the number of underweight, normal weight, and obese children was 23 (13.0\%), 144 (81.4\%), and 10 (5.6\%), respectively. The distribution of birth weight and prevalence of SGA among the underweight children were significantly different from those in normal weight children (Table 4). Notably, the prevalence of SGA in underweight children was approximately 3.8 times than that in normal weight children. Finally, for LBW children, we examined the association between being underweight at Age 5 and several variables, including sex, birth weight, height, gestational age, presence of SGA, and multiple births, by multiple logistic regression analysis (Table 5). Consequently, SGA was found to be the only factor associated with underweight at Age 5 (OR 8.14, 95\%; CI 2.01 - 32.93). 
Table 3. Differences in the prevalence of underweight and obesity between low and normal birth weight children.

\begin{tabular}{|c|c|c|c|c|c|c|c|c|c|}
\hline & \multicolumn{2}{|c|}{ Total } & \multirow{2}{*}{$P$-value ${ }^{a}$} & \multicolumn{2}{|c|}{ Boys } & \multicolumn{3}{|c|}{ Girls } & \multirow{2}{*}{$P$-value ${ }^{\text {a }}$} \\
\hline & LBW $(\mathrm{n}=177)$ & NBW $(n=2485)$ & & \multicolumn{2}{|c|}{ LBW $(n=93)$ NBW $(n=1267)$} & & \multicolumn{2}{|c|}{ LBW $(n=84)$ NBW $(n=1218)$} & \\
\hline \multicolumn{10}{|c|}{ Prevalence of underweight } \\
\hline Birth & $127(71.8)$ & $35(1.4)$ & $<0.001$ & 65 (69.9) & $21(1.7)$ & $<0.001$ & $62(73.8)$ & $14(1.1)$ & $<0.001$ \\
\hline $1.5 \mathrm{y}$ & $18(10.2)$ & $74(3.0)$ & $<0.001$ & $5(5.4)$ & $40(3.2)$ & 0.19 & $13(15.5)$ & $34(2.8)$ & $<0.001$ \\
\hline $3.5 \mathrm{y}$ & 21 (11.9) & $61(2.5)$ & $<0.001$ & $10(10.8)$ & $32(2.5)$ & $<0.001$ & $11(13.1)$ & $29(2.4)$ & $<0.001$ \\
\hline $5 y$ & $23(13.0)$ & $89(3.6)$ & $<0.001$ & $10(10.8)$ & $47(3.7)$ & $<0.01$ & $13(15.5)$ & $42(3.4)$ & $<0.001$ \\
\hline \multicolumn{10}{|c|}{ Prevalence of obesity } \\
\hline Birth & $2(1.1)$ & $270(10.9)$ & $<0.001$ & $1(1.1)$ & $126(9.9)$ & $<0.001$ & $1(1.2)$ & $144(11.8)$ & $<0.001$ \\
\hline $1.5 \mathrm{y}$ & $22(12.4)$ & $284(11.4)$ & 0.34 & $14(15.1)$ & $121(9.6)$ & 0.07 & $8(9.5)$ & $163(13.4)$ & 0.25 \\
\hline $3.5 \mathrm{y}$ & $15(8.5)$ & $211(8.5)$ & 0.55 & $12(12.9)$ & $109(8.6)$ & 0.11 & $3(3.6)$ & $102(8.4)$ & 0.08 \\
\hline $5 y$ & $10(5.6)$ & 145 (5.8) & 0.54 & $8(8.6)$ & $76(6.0)$ & 0.21 & $2(2.4)$ & $69(5.7)$ & 0.15 \\
\hline
\end{tabular}

LBW: Low Birth Weight; NBW: Normal Birth Weight. ${ }^{\text {T}}$ The prevalence of underweight and obesity between LBW and NBW children was compared by the Fisher's exact test.

Table 4. Comparison of the physical characteristics at birth by body status at 5 years in low birth weight children.

\begin{tabular}{cccc}
\hline & \multicolumn{3}{c}{ Body status at 5 years } \\
\cline { 2 - 4 } Sex (boys \%) & Thin $(\mathrm{n}=23)$ & Normal weight $(\mathrm{n}=144)$ & Obese $(\mathrm{n}=10)$ \\
\hline Birth weight $(\mathrm{kg} \pm \mathrm{SD})$ & $10(43.5)$ & $75(52.1)$ & $1.67 \pm 0.55$ \\
$\geq 1.5 \mathrm{~kg},<2.5 \mathrm{~kg}(\%)$ & $1.52 \pm 0.49$ & $1.66 \pm 0.47$ & $7(70.0)$ \\
$\geq 1.0 \mathrm{~kg},<1.5 \mathrm{~kg}(\%)$ & $10(43.5)^{\mathrm{b}}$ & $96(66.7)$ & $2(20.0)$ \\
$<1.0 \mathrm{~kg}(\%)$ & $11(47.8)^{\mathrm{b}}$ & $31(21.5)$ & $1(10.0)$ \\
Birth height $(\mathrm{cm} \pm \mathrm{SD})$ & $2(8.7)^{\mathrm{b}}$ & $17(11.8)$ & $39.6 \pm 5.0$ \\
Gestational age (wk \pm SD) & $39.6 \pm 4.3$ & $40.4 \pm 4.0$ & $31.7 \pm 3.8$ \\
SGA $^{\mathrm{a}}(\%)$ & $34.0 \pm 3.6$ & $32.6 \pm 3.5$ & $0(0.0)$ \\
\hline
\end{tabular}

${ }^{\text {a }}$ SGA: Small for gestational age, defined as a sex-specific birth height and weight below the $10^{\text {th }}$ percentile for gestational age of the Japanese standard; 'bignificantly different from normal-weight children, $P<0.05$ (Fisher's exact test); 'Significantly different from normal-weight children, $P<$ 0.001 (Fisher's exact test).

\section{Discussion}

Monitoring growth and neurological development are key issues in the follow-up of LBW children [3]. Investigators have reported retarded height and weight growth among LBW, especially in VLBW children [10] [11]. Although most LBW children experience catch-up growth by adolescence, the precise time of catch-up is highly diverse and appears to depend on their weight and gestational age at birth [6]-[9]. In fact, several studies have reported that SGA infants were more likely to remain smaller throughout childhood and adulthood than infants born at weights appropriate for gestational age (AGA) [8] [11] [28].

In the present study, we demonstrated that LBW children experienced accelerated growth from birth to age 3.5 years, but that they still had significantly smaller height and weight z-scores than the NBW controls, regardless of sex, at Age 5. These results were consistent with those of previous studies, in which preterm or VLBW children showed steady increases in height and weight standard deviation scores from birth to Age 6, but that they remained smaller and lighter than their term-born or NBW peers [8] [29]. In addition, adolescents and 
Table 5. Multiple logistic regression of the association between underweight at 5 years and physical characteristics at birth in low birth weight children.

\begin{tabular}{ccccc}
\hline \multirow{2}{*}{ Dependent variables } & \multicolumn{3}{c}{ Independent variable: Underweight at 5 years } \\
\cline { 2 - 4 } & Coefficient $(95 \% \mathrm{CI})$ & Standardized coefficient & OR (95\% CI) & $P$-value \\
\hline Sex $^{\mathrm{a}}$ & $0.02(-0.98,1.03)$ & 0.01 & $1.02(0.38,2.79)$ & 0.95 \\
Birth weight $(\mathrm{kg})$ & $0.31(-1.24,1.87)$ & 0.15 & $1.37(0.29,6.47)$ & 0.67 \\
Birth height (cm) & $-0.12(-0.33,0.10)$ & -0.46 & $0.89(0.72,1.11)$ & 0.32 \\
Gestational age (wk) & $0.05(-0.22,0.31)$ & 0.16 & $1.05(0.80,1.36)$ & 0.79 \\
SGA & $2.10(0.70,3.49)$ & 0.91 & $0.14(2.01,32.93)$ & $<0.001$ \\
Muptiple births & $-0.83(-2.43,0.78)$ & -0.33 & $0.44(0.09,2.17)$ & 0.35 \\
\hline
\end{tabular}

Ten obese children were excluded from this analysis. ${ }^{a}$ For the analysis, 1: Boys, 0: Girls, 1: AGA, 0: AGA, 1: Multiple births, 0: Single birth, were allocated. 'SGA: Small for gestational age, defined as a sex-specific birth height and weight below the 10th percentile for gestational age of the Japanese standard.

adults born preterm or LBW have also been shown to be shorter and lighter than their peers [9] [10] [28] [30] [31]. For example, Saigal et al. [31] reported that the mean height of young adults born extremely LBW ( $<1.0$ $\mathrm{kg}$ ) was below their target height.

Since catch-up growth for height and weight is not necessarily proportionate [30], it is important to assess BMI for judgment of adiposity. Although underweight should be evaluated using the BMI, epidemiological studies on the prevalence of underweight in LBW children based on BMI are limited. Hack et al. [28] demonstrated that $6 \%$ of VLBW males were underweight (BMI < 18.5) compared with $2 \%$ of their controls at Age 20. Equally, Yang et al. [32] showed that $7.77 \%$ and $1.46 \%$ of children whose birth weights were $<2.5$ and $\geq 2.5 \mathrm{~kg}$, respectively, were underweight at Ages 3 - 6, according to the National Center for Health Statistics standards and that LBW children were at higher risk for underweight (OR 3.68, 95\% CI 3.11 - 4.37). Additionally, the prevalence of underweight (BMI $<5^{\text {th }}$ percentile) in extremely LBW children has been reported to be significantly higher in girls at Age 8, becoming similar to that of NBW children at Age 14 [33]. For both sexes, the mean BMI of young adults born preterm or extremely LBW was close to that of the reference population in most previous studies [10] [31]. However, another study showed lower BMIs among only males at 20 years [28].

When comparing LBW and NBW children, we found a significant difference only in BMI percentiles for girls, except for at birth. A possible reason for this difference between the sexes was that the prevalence of SGA was significantly higher in LBW girls compared with that in LBW boys. The prevalence of underweight was significantly higher at Age 5 in both sexes, and the multiple regression analysis indicated that SGA at birth was only associated with underweight in 5-year-old children. Indeed, a review of childhood undernutrition risk based on SGA and preterm birth found that SGA, irrespective of gestational age, was risk factor for underweight at 12 60 months compared with AGA or term births [34].

A number of studies have examined the relationship between birth weight and overweight or obesity [31] [33] [35]-[39]. Several studies have reported that LBW was a protective factor against overweight or obesity in infancy, particularly in girls [35], or in childhood [36]. Hirschler et al. [36] showed that by school age, LBW children of both sexes had almost $70 \%$ lower odds of being overweight or obese. Other investigators have demonstrated higher BMIs in females born at low birth weights [37] and higher rates of obesity in LBW adults [38]. In addition, Eriksson et al. [38] demonstrated J-shaped associations in males, with a higher prevalence of obesity observed for LBW and higher birth weight than in those with a birth weight of $3.0-3.5 \mathrm{~kg}$. In contrast, there were no differences in the prevalence of overweight or obesity in childhood and adolescence [33], or young adulthood [31], between extremely LBW and NBW subjects. Finally, in a systematic review and meta-analysis of the association between birth weight and subsequent risk of obesity, Yu et al. [39] found no evidence for a significant association between LBW and obesity. Taken together, these findings suggest that the association between LBW and later-life obesity remains controversial. The present study found similar obesity rates between 1.5 and 5 years of age in LBW and NBW children. However, further follow-up to adolescence and adulthood is neces- 
sary, given that obesity and its related disorders seem to appear later in life [11] [12] [19] [20].

There are several limitations in the present study. First, the retrospective design resulted in a substantial number of children without present addresses at the time of investigation and a questionnaire return rate of approximately 37\%. In addition, the investigation was carried out at single hospital in the Nara Prefecture. These facts undoubtedly led to a degree of selection bias that must be considered in any interpretation. Second, we followed the growth of LBW children from birth to Age 5 only, making a longer follow-up study to later childhood or adulthood necessary. Third, the study collected only height and weight as anthropometric measures and used BMI as the sole indicator for assessing adiposity in children. Other anthropometric indicators, such as waist circumference [40], lean and fat mass [41], or visceral and subcutaneous fat [41], may be required to ensure precise evaluation.

A major strength of this study was that it examined the growth of LBW children from birth to Age 5 longitudinally. Moreover, the data for LBW children were compared with a large sample of NBW children, with particular attention given to the prevalence of both underweight and obesity. The accuracy of the data obtained from mother-health child records maintained by the mother is also considered as strength. In Japan, a regular health check is carried out by experts at birth and at Ages 1.5 and 3.5 years, and the results are recorded in these notebooks.

\section{Conclusion}

The prevalence of underweight was higher in LBW children than in NBW controls, but the rates of obesity were comparable. Thus, our data support underweight being a more serious problem than obesity in LBW children at Age 5. The facts that height and weight z-scores were significantly lower at each time point, and that SGA was the only risk factor for underweight at Age 5, were important findings. These suggest that careful observation of growth and intervention from early infancy may be necessary to prevent the development of underweight.

\section{Competing Interests}

The authors declare that they have no competing interests.

\section{Acknowledgements}

The authors would like to thank the participants in the study. The authors would also like to thank Enago (www.enago.jp) for the English language reviews.

\section{References}

[1] Horbar, J.D., Badger, G.J., Carpenter, J.H., Fanaroff, A.A., Kilpatrick, S., LaCorte, M., et al. (2002) Trends in Mortality and Morbidity for Very Low Birth Weight Infants, 1991-1999. Pediatrics, 110, 143-151. http://dx.doi.org/10.1542/peds.110.1.143

[2] Kusuda, S., Fujimura, M., Uchiyama, A., Totsu, S. and Matsunami, K. (2012) Trends in Morbidity and Mortality among Very-Low-Birth-Weight Infants from 2003 to 2008 in Japan. Pediatric Research, 72, 531-538. http://dx.doi.org/10.1038/pr.2012.114

[3] Saigal, S. and Doyle, L.W. (2008) An Overview of Mortality and Sequelae of Preterm Birth from Infancy to Adulthood. Lancet, 371, 261-269. http://dx.doi.org/10.1016/S0140-6736(08)60136-1

[4] United Nations Children’s Fund (UNICEF) (2013) Child Well-Being in Rich Countries: A Comparative Overview. http://www.unicef-irc.org/publications/pdf/rc11_eng.pdf\#search='United+Nations+Children\%E2\%80\%99s+Fund+\%2 8UNICEF\%29.+Child+wellbeing+in+rich+countries

[5] Yoshida, H., Kato, N. and Yokoyama, T. (2014) Current Trends in Low Birth Weight Infants in Japan. Journal of the National Institute of Public Health, 63, 2-16. (In Japanese)

[6] Monset-Couchard, M. and de Bethmann, O. (2000) Catch-Up Growth in 166 Small-for-Gestational Age Premature Infants Weighing Less than $1000 \mathrm{~g}$ at Birth. Biology of the Neonate, 78, 161-167. http://dx.doi.org/10.1159/000014265

[7] Itabashi, K., Mishina, J., Tada, H., Sakurai, M., Nanri, Y. and Hirohata, Y. (2007) Longitudinal Follow-Up of Height up to Five Years of Age in Infants Born Preterm Small for Gestational Age; Comparison to Full-Term Small for Gestational Age Infants. Early Human Development, 83, 327-333. http://dx.doi.org/10.1016/j.earlhumdev.2006.07.002

[8] Trebar, B., Traunecker, R., Selbmann, H.K. and Ranke, M.B. (2007) Growth during the First Two Years Predicts Pre- 
School Height in Children Born with Very Low Birth Weight (VLBW): Results of a Study of 1320 Children in Germany. Pediatric Research, 62, 209-214. http://dx.doi.org/10.1203/PDR.0b013e3180ca7c5b

[9] Doyle, L.W., Faber, B., Callanan, C., Ford, G.W. and Davis, N.M. (2004) Extremely Low Birth Weight and Body Size in Early Adulthood. Archives of Disease in Childhood, 89, 347-350. http://dx.doi.org/10.1136/adc.2002.025924

[10] Roberts, G., Cheong, J., Opie, G., Carse, E., Davis, N., Duff, J., et al. (2013) Growth of Extremely Preterm Survivors from Birth to 18 Years of Age Compared with Term Controls. Pediatrics, 131, 439-445. http://dx.doi.org/10.1542/peds.2012-1135

[11] Casey, P.H. (2008) Growth of Low Birth Weight Preterm Children. Seminars in Perinatology, 32, 20-27. http://dx.doi.org/10.1053/j.semperi.2007.12.004

[12] Kelishadi, R. and Poursafa, P. (2014) A Review on the Genetic, Environmental, and Lifestyle Aspects of the Early-Life Origins of Cardiovascular Disease. Current Problems in Pediatric and Adolescent Health Care, 44, 54-72. http://dx.doi.org/10.1016/j.cppeds.2013.12.005

[13] Barker, D.J.P., Winter, P.D., Osmond, C., Margetts, B. and Simmonds, S.J. (1989) Weight in Infancy and Death from Ischaemic Heart Disease. The Lancet, 2, 577-580. http://dx.doi.org/10.1016/S0140-6736(89)90710-1

[14] Euser, A.M., Finken, M.J.J., Keijzer-Veen, M.G., Hille, E.T., Wit, J.M. and Dekker, F.W. (2005) Associations between Prenatal and Infancy Weight Gain and BMI, Fat Mass, and Fat Distribution in Young Adulthood: A Prospective Cohort Study in Males and Females Born Very Preterm. The American Journal of Clinical Nutrition, 81, 480-487.

[15] Huxley, R.R., Shiell, A.W. and Law, C.M. (2000) The Role of Size at Birth and Postnatal Catch-Up Growth in Determining Systolic Blood Pressure: A Systematic Review of the Literature. Journal of Hypertension, 18, 815-831. http://dx.doi.org/10.1097/00004872-200018070-00002

[16] Regan, F.M., Cutfield, W.S., Jefferies, C., Robinson, E. and Hofman, P.L. (2006) The Impact of Early Nutrition in Premature Infants on Later Childhood Insulin Sensitivity and Growth. Pediatrics, 118, 1943-1949. http://dx.doi.org/10.1542/peds.2006-0733

[17] Nobili, V., Alisi, A., Panera, N. and Agostoni, C. (2008) Low Birth Weight and Catch-up-Growth Associated with Metabolic Syndrome: A Ten Year Systematic Review. Pediatric Endocrinology Reviews, 6, 241-247.

[18] Eriksson, J.G., Forsén, T., Tuomilehto, J., Osmond, C. and Barker, D.J.P. (2001) Early Growth and Coronary Heart Disease in Later Life: Longitudinal Study. BMJ, 322, 949-953. http://dx.doi.org/10.1136/bmj.322.7292.949

[19] Barker, D.J.P. and Osmond, C. (1986) Infant Mortality, Childhood Nutrition, and Ischaemic Heart Disease in England and Wales. The Lancet, 1, 1077-1081. http://dx.doi.org/10.1016/S0140-6736(86)91340-1

[20] Gluckman, P.D. and Hanson, H.A. (2004) Living with the Past: Evolution, Development, and the Patterns of Disease. Science, 305, 1733-1736. http://dx.doi.org/10.1126/science.1095292

[21] Kato, R., Kubota, M., Higashiyama, Y. and Nagai, A. (2014) Longitudinal Study of Thinness from Birth to Early Childhood: The Association with Parental Thinness. Acta Paediatrica, 103, 1285-1289. http://dx.doi.org/10.1111/apa.12810

[22] Kato, N. (2009) Construction of BMI for Age References for Japanese Children from the 2000 National Growth Survey. Journal of Japanese Association for Human Auxology, 15, 37-44.

[23] Must, A., Dallal, G.E. and Dietz, W.H. (1991) Reference Data for Obesity: 85th and 95th Percentiles of Body Mass Index (wt/ht $\left.{ }^{2}\right)$ and Triceps Skinfold Thickness. The American Journal of Clinical Nutrition, 53, 839-846.

[24] Wang, Y., Monteiro, C. and Popkin, B.M. (2002) Trends of Obesity and Underweight in Older Children and Adolescents in the United States, Brazil, China, and Russia. The American Journal of Clinical Nutrition, 75, 971-977.

[25] Mak, K.K. and Tan, S.H. (2012) Underweight Problems in Asian Children and Adolescents. European Journal of Pediatrics, 171, 779-785. http://dx.doi.org/10.1007/s00431-012-1685-9

[26] Cole, T.J., Bellizzi, M.C., Flegal, K.M. and Dietz, W.H. (2000) Establishing a Standard Definition for Child Overweight and Obesity Worldwide: International Survey. BMJ, 320, 1240-1245. http://dx.doi.org/10.1136/bmj.320.7244.1240

[27] Matsuzawa, Y., Inoue, S., Ikeda, Y., Sakata, T., Saito, Y., Sato, Y., et al. (2000) A New Criteria of Judgment of Obesity and Diagnosis of Pathological Obesity. Journal of Japan Society for the Study of Obesity, 6, 18-28. (In Japanese)

[28] Hack, M., Shuluchter, M., Cartar, L., Rahman, M., Cuttler, L. and Borawski, E. (2003) Growth of Very Low Birth Weight Infants to Age 20 Years. Pediatrics, 112, 30-38.http://dx.doi.org/10.1542/peds.112.1.e30

[29] Bracewell, M.A., Hennessy, E.M., Wolke, D. and Marlow, N. (2008) The EPI Cure Study: Growth and Blood Pressure at 6 Years of Age Following Extremely Preterm Birth. Archives of Disease in Childhood Fetal and Neonatal Edition, 93, 108-114. http://dx.doi.org/10.1136/adc.2007.118596

[30] Euser, A.M., Wit, C.C., Finken, M.J.J., Rijken, M. and Wit, J.M. (2008) Growth of Preterm Born Children. Hormone Research, 70, 319-328. http://dx.doi.org/10.1159/000161862 
[31] Saigal, S., Stoskopf, B., Streiner, D., Paneth, N., Pinelli, J. and Boyle, M. (2006) Growth Trajectories of Extremely Low Birth Weight Infants from Birth to Young Adulthood: A Longitudinal, Population-Based Study. Pediatric Research, 60, 751-758. http://dx.doi.org/10.1203/01.pdr.0000246201.93662.8e

[32] Yang, X.L., Ye, R.W., Zheng, J.C., Jin, L., Liu, J.M. and Ren, A.G. (2010) Analysis on Influencing Factors for Stunting and Underweight among Children Aged 3-6 Years in 15 Counties of Jiangsu and Zhejiang Provinces. Chinese Journal of Epidemiology, 31, 506-509. (In Chinese)

[33] Hack, M., Schluchter, M., Margevicius, S., Andreias, L., Taylor, G. and Cuttler, L. (2014) Trajectory and Correlates of Growth of Extremely Low Birth Weight Adolescents. Pediatric Research, 75, 358-366. http://dx.doi.org/10.1038/pr.2013.209

[34] Christian, P., Lee, S.E., Angel, M.D., Adair, L.S., Arifeen, S.E., Ashorn, P., et al. (2013) Risk of Childhood Undernutrition Related to Small-for-Gestational Age and Preterm Birth in Low- and Middle-Income Countries. International Journal of Epidemiology, 42, 1340-1355. http://dx.doi.org/10.1093/ije/dyt109

[35] Oldroyd, J., Renzaho, A. and Skouteris, H. (2011) Low and High Birth Weight as Risk Factors for Obesity among 4 to 5-Year-Old Australian Children: Does Gender Matter? European Journal of Pediatrics, 170, 899-906. http://dx.doi.org/10.1007/s00431-010-1375-4

[36] Hirschler, V., Bugna, J., Roque, M., Gilligan, T. and Gonzalez, C. (2008) Does Low Birth Weight Predict Obesity/ Overweight and Metabolic Syndrome in Elementary School Children? Archives of Medical Research, 39, 796-802. http://dx.doi.org/10.1016/j.arcmed.2008.08.003

[37] Curhan, G.C., Chertow, G.M., Willett, W.C., Spiegelman, D., Colditz, G.A., Manson, J.E., et al. (1996) Birth Weight and Adult Hypertension and Obesity in Women. Circulation, 94, 1310-1315. http://dx.doi.org/10.1161/01.CIR.94.6.1310

[38] Eriksson, J., ForseÂn, T., Tuomilehto, J., Osmond, C. and Barker, D. (2001) Size at Birth, Childhood Growth and Obesity in Adult Life. International Journal of Obesity, 25, 735-740. http://dx.doi.org/10.1038/sj.ijo.0801602

[39] Yu, Z.B., Han, S.P., Zhu, G.Z., Zhu, C., Wang, X.J., Cao, X.G., et al. (2011) Birth Weight and Subsequent Risk of Obesity: A Systematic Review and Meta-Analysis. Obesity Reviews, 12, 525-542. http://dx.doi.org/10.1111/j.1467-789X.2011.00867.x

[40] Stephen, R.D., Philip, R.K. and John, A.M. (2000) Utility of Different Measures of Body Fat Distribution in Children and Adolescents. American Journal of Epidemiology, 152, 1179-1184. http://dx.doi.org/10.1093/aje/152.12.1179

[41] Ibáñez, L., Lopez-Bermejo, A., Suárez, L., Marcos, M.V., Díaz, M. and de Zegher, F. (2008) Visceral Adiposity without Overweight in Children Born Small for Gestational Age. The Journal of Clinical Endocrinology Metabolism, 93, 2079-2083. http://dx.doi.org/10.1210/jc.2007-2850 